Article

\title{
Synthesis and Electrocatalytic Performance of Multi-Component Nanoporous PtRuCuW Alloy for Direct Methanol Fuel Cells
}

Xiaoting Chen ${ }^{1, \dagger}$, Hao Wang ${ }^{1, \dagger}$, Ying Wang ${ }^{1}$, Qingguo Bai ${ }^{1}$, Yulai Gao ${ }^{2}$ and Zhonghua Zhang ${ }^{1, *}$

1 Key Laboratory for Liquid-Solid Structural Evolution and Processing of Materials (Ministry of Education), School of Materials Science and Engineering, Shandong University, Jingshi Road 17923, Jinan 250061, China; E-Mails: sdu12chxt@gmail.com (X.C.); beishangdehonghu@163.com (H.W.); wy18766311718@163.com (Y.W.); baychrist@163.com (Q.B.)

2 Laboratory for Microstructures, Shanghai University, 99 Shangda Road, Shanghai 200436, China; E-Mail: ylgao@shu.edu.cn

$\dagger$ These authors contributed equally to this work.

* Author to whom correspondence should be addressed; E-Mail: zh_zhang@sdu.edu.cn; Tel./Fax: +86-531-88396978.

Academic Editor: Minhua Shao

Received: 28 April 2015 / Accepted: 16 June 2015 / Published: 24 June 2015

\begin{abstract}
We have prepared a multi-component nanoporous PtRuCuW (np-PtRuCuW) electrocatalyst via a combined chemical dealloying and mechanical alloying process. The X-ray diffraction (XRD), transmission electron microscopy (TEM) and electrochemical measurements have been applied to characterize the microstructure and electrocatalytic activities of the np-PtRuCuW. The np-PtRuCuW catalyst has a unique three-dimensional bi-continuous ligament structure and the length scale is $2.0 \pm 0.3 \mathrm{~nm}$. The np-PtRuCuW catalyst shows a relatively high level of activity normalized to mass $\left(467.1 \mathrm{~mA} \mathrm{mgPt}^{-1}\right)$ and electrochemically active surface area $\left(1.8 \mathrm{~mA} \mathrm{~cm}{ }^{-2}\right)$ compared to the state-of-the-art commercial $\mathrm{PtC}$ and $\mathrm{PtRu}$ catalyst at anode. Although the $\mathrm{CO}$ stripping peak of np-PtRuCuW $0.47 \mathrm{~V}$ ( vs. saturated calomel electrode, SCE) is more positive than PtRu, there is a $200 \mathrm{mV}$ negative shift compared to $\mathrm{PtC}(0.67 \mathrm{~V}$ vs. SCE). In addition, the half-wave potential and specific activity towards oxygen reduction of np-PtRuCuW are $0.877 \mathrm{~V}$ ( $v$ s. reversible hydrogen electrode, RHE) and $0.26 \mathrm{~mA} \mathrm{~cm}{ }^{-2}$, indicating a great enhancement towards oxygen reduction than the commercial PtC.
\end{abstract}


Keywords: direct methanol fuel cells; methanol oxidation; oxygen reduction reaction; dealloying; nanoporous alloys

\section{Introduction}

In recent decades, there are increasing requirements for high-efficiency and eco-friendly energy to cope with environment problems, such as the depletion of energy and pollution. Direct methanol fuel cells (DMFCs) meet the above requirement and are important for the automotive industry [1,2]. As an important component, the state-of-the-art electrocatalysts must ensure the methanol oxidation reaction (MOR) at anode and oxygen reduction reaction (ORR) at cathode to generate electricity with water and carbon dioxide as the byproducts [1,3]. The use of current catalysts has several disadvantages including the low catalytic efficiency as well as $\mathrm{CO}$ tolerance, and sluggish kinetics towards ORR. Much effort has been dedicated to alloying Pt with other metals (e.g., Fe [4], Co [5-7], $\mathrm{Ni}[5,8,9], \mathrm{Cu}[10], \mathrm{Sn}[11]$, etc.) to improve electrochemical activities. For high-activity applications of DMFCs, PtRu alloy remains the most active electrocatalyst due to its unique reaction mechanism [12,13]. Based upon the bi-functional and electronic effects [14-16], the electrocatalytic performance of catalysts could be significantly enhanced through compositional design of catalysts. For instance, W/Mo-modified PtRu/C showed improved electro-oxidation activity in comparison to the un-modified PtRu/C [17]. The PtRuOsIr showed better activity compared to PtRuOs and PtRuIr [3].

Traditional preparation methods for Pt-based alloys have been focusing on microemulsions [18,19], microwave irradiation [20], electrodeposition [21] and chemical reduction [3,22]. These processes are limited to the tunability of alloy composition, cockamamie, and not suitable for batch production, which hampers the commercialization of DMFCs. Thus, although there are obvious advantages in multicomponent catalysts, most of the prior studies were restricted to the synthesis of binary and ternary alloys. In contrast, facile dealloying has shown its advantage in preparing nanoporous metals/alloys. Thus, materials with unique nanoporous structure possess intriguing physical and chemical properties to generate promising potentials for various important applications such as sensors [23], mechanical actuators [24] and catalysis [25,26].

From the viewpoint of activity and accessibility, $\mathrm{Cu}$ are $\mathrm{W}$ are superior candidates as indispensible component in catalysts. In previous work, $\mathrm{PtRuCu}$ [27,28] and $\mathrm{PtRuW}[29,30]$ ternary alloys have received unremitting interest. As part of the continuing effort in new catalyst exploration, the nanoporous PtRuCuW (np-PtRuCuW) alloy was synthesized through mechanical alloying and subsequent mild chemical dealloying process in the present paper. This new catalyst was characterized with electrochemical measurements at the anode as well as cathode for DMFCs. Our results show that the np-PtRuCuW catalyst performs better than the commercial PtC and PtRu catalysts. Furthermore, the catalyst can be synthesized in gram-scale, which makes repeatable experiments in laboratory possible and batch preparation in factory reliable. Given the advantages, including easy access to component design, simplicity in the fabrication process and the enhanced activity, we hope that the combination of mechanical alloying with dealloying provides an efficient way to design multicomponent catalyst materials. 


\section{Results and Discussion}

\subsection{Microstructural Characterization of $n p-P t R u C u W$}

Figure 1 shows the X-ray diffraction (XRD) patterns of the $\mathrm{Al}_{66} \mathrm{Cu}_{30}\left(\mathrm{Pt}_{53} \mathrm{Ru}_{32} \mathrm{~W}_{15}\right)_{4}$ precursor alloy and the as-dealloyed samples. In Figure 1a, a number of diffraction peaks appear on the pattern of the as-milled $\mathrm{Al}_{66} \mathrm{Cu}_{30}\left(\mathrm{Pt}_{53} \mathrm{Ru}_{32} \mathrm{~W}_{15}\right)_{4}$ precursor, which can be ascribed to a $\mathrm{Al}_{4} \mathrm{Cu}$-type (PDF No. 65-3347) intermetallic phase and Ru (PDF No. 06-0663). In addition, there is a sharp peak around scattering angles $(2 \theta)$ of $c a .40^{\circ}$ which can be ascribed to PtRu. A little amount of Ru dissolved during the dealloying process, leading to the reduction of peak intensity and increase of peak width around

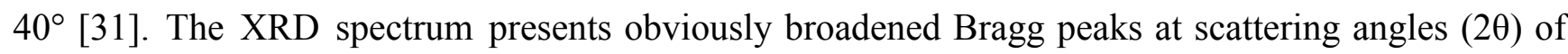
ca. $40.8^{\circ}, 47.1^{\circ}$ and $69.4^{\circ}$ (Figure $1 \mathrm{~b}$ ) compared to the precursor alloy. These signals consist with the face-centered cubic (f.c.c.) Pt (PDF No. 04-0802) in spite of the shifting of Bragg peaks. In addition, the $\mathrm{Ru}$ diffraction peaks still exist after dealloying (Figure 1b). Due to the minor addition of Ru (only 1.28 at \%) into the precursor, the strong diffraction peaks of $\mathrm{Ru}$ also suggest the alloying of other elements (Pt, W and $\mathrm{Al}$ ) with $\mathrm{Ru}$ to form a solid solution. Also, it is understandable to assume that the alloying of $\mathrm{Pt}$ with $\mathrm{Ru}$ as well as $\mathrm{Cu}$ and $\mathrm{W}$ results in the shift towards higher Bragg angles [32]. The chemical component of the as-dealloyed samples was characterized by EDX and one typical spectrum is presented in Figure 1c. The corresponding results reveal that the sample is composed of $\mathrm{Pt}$ (56.2 at \%), $\mathrm{Ru}(18.7$ at \%), $\mathrm{Cu}(14.2$ at \%) and $\mathrm{W}$ (10.9 at \%), with a minor residual Al (only few atom percent) could be detected in the as-dealloyed samples.
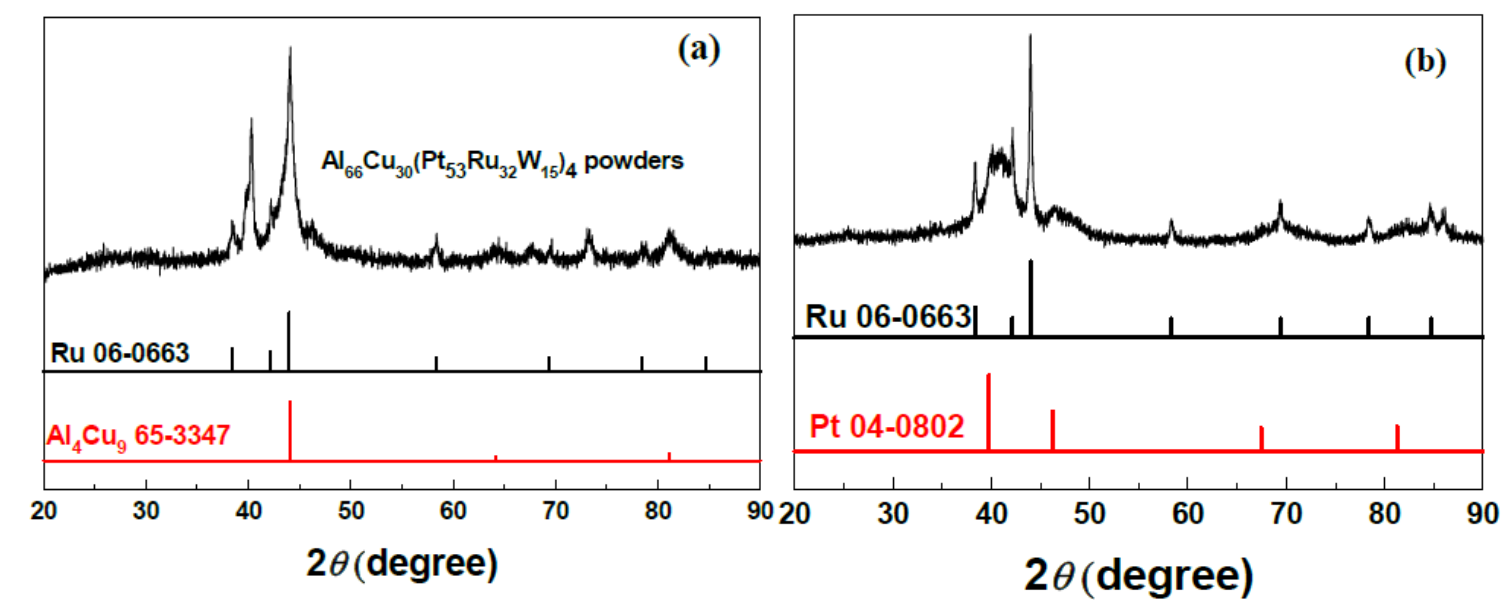

Figure 1. Cont. 


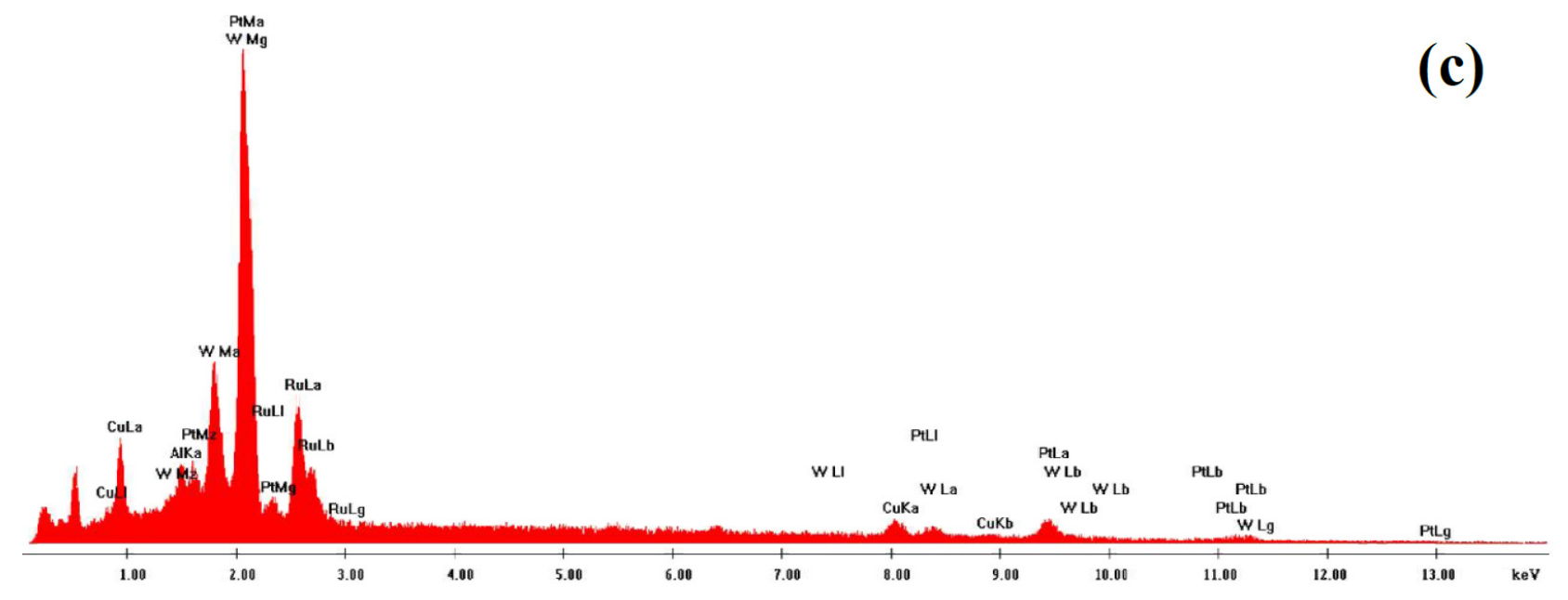

Figure 1. XRD spectrum of (a) the mechanically alloyed $\mathrm{Al}_{66} \mathrm{Cu} \mathrm{Cu}_{30}\left(\mathrm{Pt}_{53} \mathrm{Ru}_{32} \mathrm{~W}_{15}\right)_{4}$ powders; (b) the precursor alloy after dealloying in the $1 \mathrm{M} \mathrm{HNO}_{3}$ solution; and (c) corresponding EDX result of the as-dealloyed samples.

As shown in Figure 2a,b, the final samples display a nanoporous structure composed of interconnected nanoscaled ligaments $(2.0 \pm 0.3 \mathrm{~nm}$ in size $)$ and bi-continuous channels. Besides the ultrafine ligament/channel structure, nanoparticles embedded in the nanoporous matrix are observed, and one particle is marked by a red arrow in Figure $2 \mathrm{~b}$. The unique nanostructure results from the dealloying process and similar phenomenon has been studied before [33,34]. The diffraction rings come from the nanoporous matrix and correspond to (111), (200), (220) and (311) reflections of f.c.c. $\mathrm{Pt}$ and the diffraction spots originate from the embedded nanoparticles corresponding to the $\mathrm{Ru}$ phase (inset of Figure 2a). Overall, the transmission electron microscopy (TEM) results are consistent with the XRD results from Figure $1 b$.

The high-resolution TEM (HRTEM) images show typical bi-continuous ligament-channel structure of the as-dealloyed samples (Figure 2c,d). The ligaments are composed of small nanocrystals of several nanometers and the spacing of some lattice fringes is $0.222 \mathrm{~nm}$ (as indicated in Figure 2d), which is similar to the (111) crystal plane of f.c.c. Pt $(\sim 0.226 \mathrm{~nm})$. The corresponding fast Fourier transform (FFT) pattern further verifies the nanocrystalline character of the selected area (presented in the inset of Figure 2d). In addition, Figure $2 d$ also shows the HRTEM image of another area. The lattice spacing of these regular lattice fringes running across the area is $0.232 \mathrm{~nm}$, which is close to the value of $\mathrm{Ru}(100)$ crystal plane $(0.234 \mathrm{~nm})$. Both the XRD and TEM results confirm that partial $\mathrm{Ru}$ failed to be alloyed with Pt and the final as-dealloyed samples include Ru and Pt solid solution. The np-PtRuCuW can be used as abbreviation for the obtained samples. 


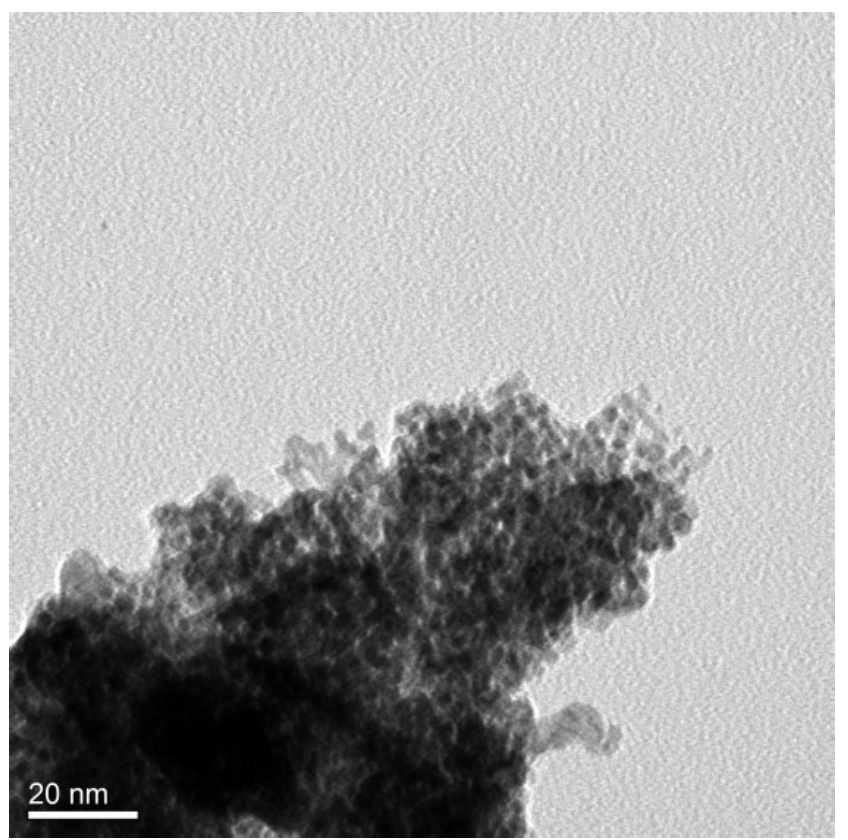

(a)

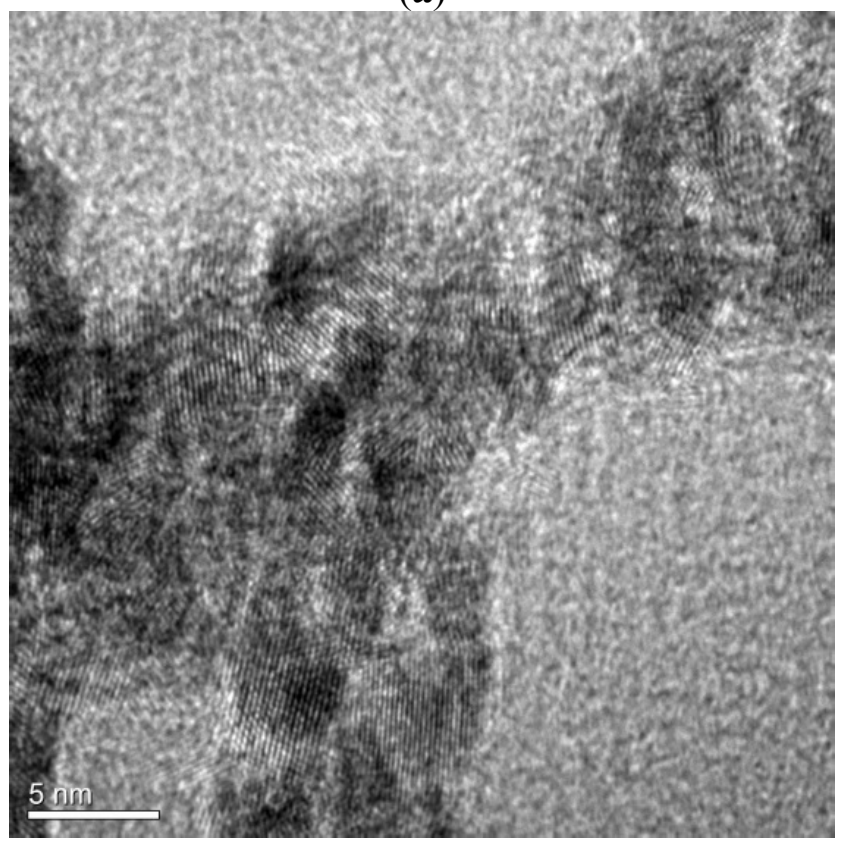

(c)

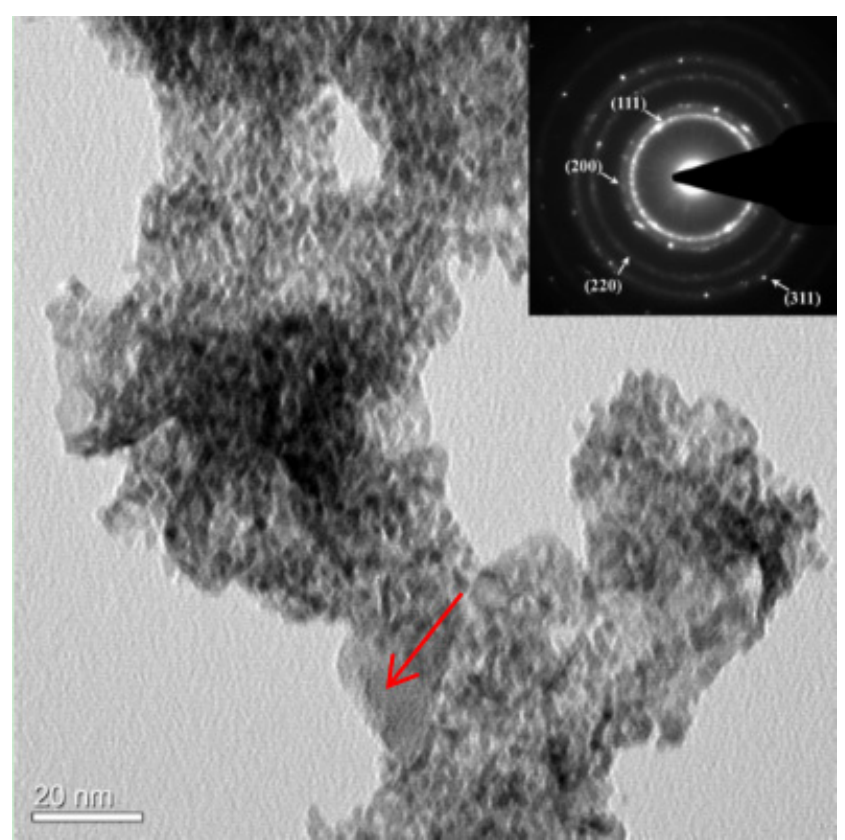

(b)

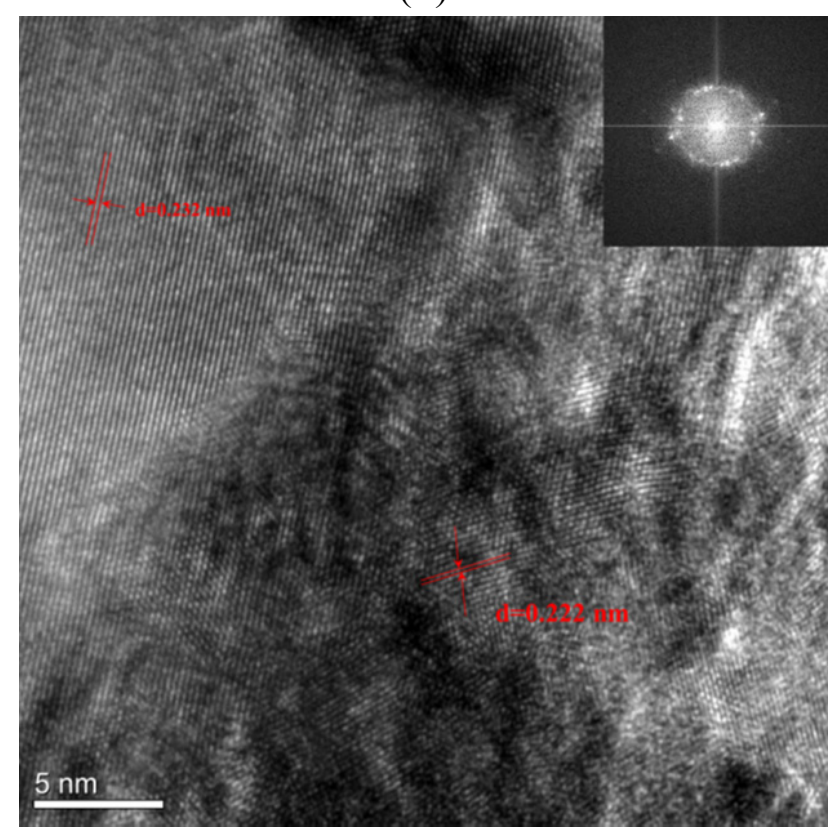

(d)

Figure 2. (a,b) TEM and (c,d) HRTEM images of the np-PtRuCuW alloy with nanoporous microstructure; Insets in (b,d): typical SAED and FFT spectrums, respectively.

\subsection{Catalytic Activity of np-PtRuCuW at Anode}

The activation step results in the catalyst surface cleaning and typical electrochemical features including the typical hydrogen ad/desorption, double layer and metallic redox region [35]. In addition, less-noble metals dissolution would happen when applying potential cycling to multi-metallic alloys [32,36,37]. For np-PtRuCuW, the CV features are different from the PtC and PtRu catalysts (Figure 3a). Firstly, there are broader double electric layer and a more featureless shoulder region than $\mathrm{PtC}$. Moreover, the reduction peak of Pt oxides shifts to a more positive direction compared to the PtC and PtRu catalysts (as highlighted by dotted line in Figure 3a). The characteristics are typical to 
multi-component alloys [7,27,32,36,37]. Normally, the electrochemically active surface area (ECSA) can be obtained from the equation ECSAPt $\left(\mathrm{m}^{2} / \mathrm{g}\right)=Q_{\mathrm{H}} /(2.1 \times \mathrm{mPt})$ by integrating the hydrogen $\mathrm{ad} /$ desorption charge and using the value of $2.1 \mathrm{C} \mathrm{m}^{-2}$ for the oxidation of a monolayer of hydrogen on a polycrystalline Pt electrode [35,38]. The ECSAs of the np-PtRuCuW, PtC and PtRu catalysts were determined to be 26,47 and $40 \mathrm{~m}^{2} \mathrm{~g}^{-1}$.

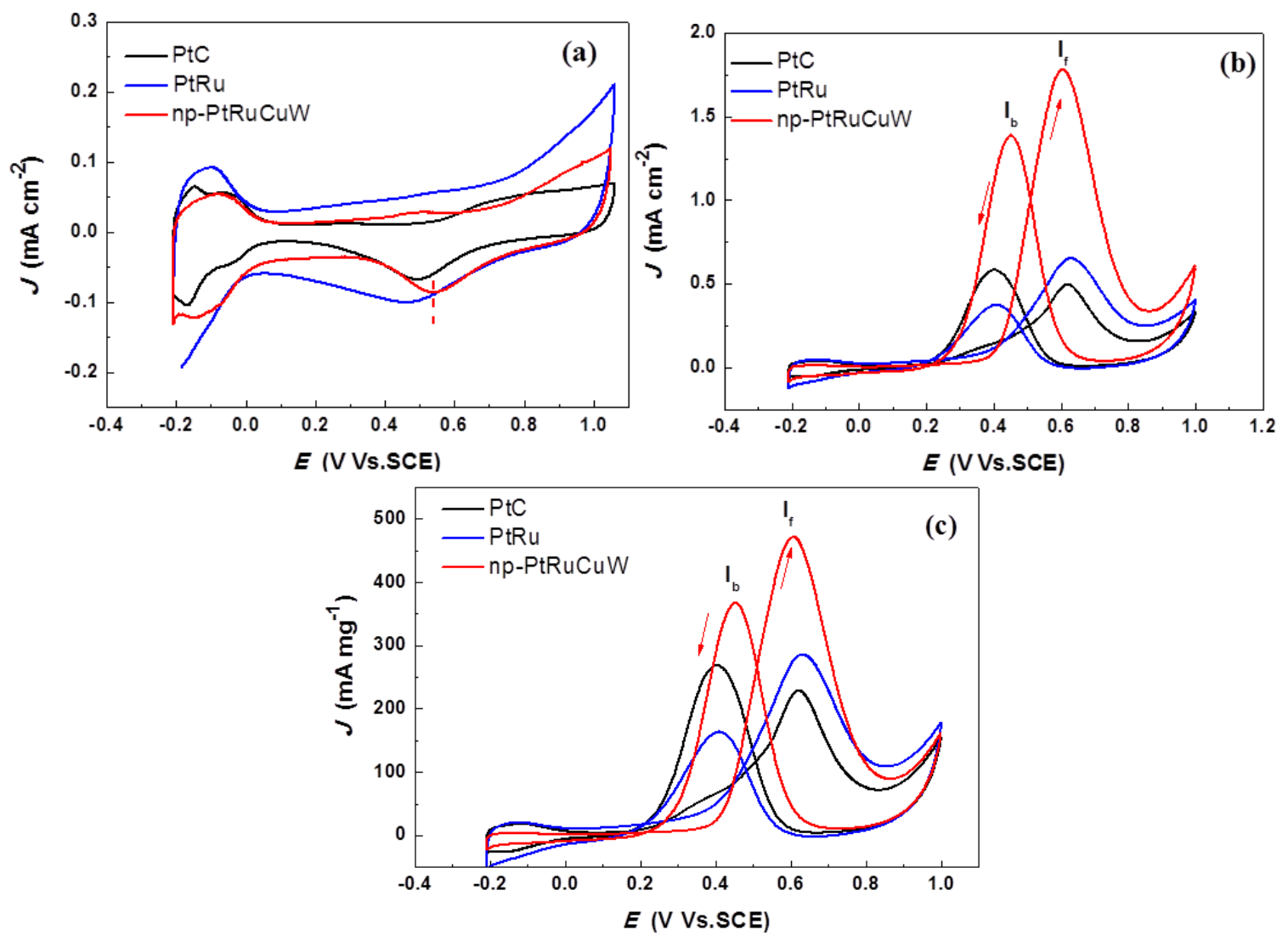

Figure 3. (a) The stable CVs of the np-PtRuCuW, PtC and PtRu catalysts in the $\mathrm{N}_{2}$ purged $0.5 \mathrm{M} \mathrm{H}_{2} \mathrm{SO}_{4}$ solution (Scan rate: $50 \mathrm{mV} \mathrm{s}^{-1}$ ); and (b) ECSA- and (c) mass-normalized activities of the np-PtRuCuW, PtC and PtRu catalysts for methanol oxidation. (Scan rate: $50 \mathrm{mV} \mathrm{s}^{-1}$ ).

Figure 3b,c shows the ECSA- and Pt mass-normalized results for the np-PtRuCuW, PtC and PtRu catalysts in the $\mathrm{H}_{2} \mathrm{SO}_{4}$ solution contain $0.5 \mathrm{M} \mathrm{CH}_{3} \mathrm{OH}$. As shown in Figure 3b, the specific activity of the np-PtRuCuW is $1.8 \mathrm{~mA} \mathrm{~cm}{ }^{-2}$, which is 3.6 and 2.9 times that of the PtC and PtRu catalysts ( 0.5 and $0.63 \mathrm{~mA} \mathrm{~cm}^{-2}$ ), respectively. Further comparison according to Pt mass (Figure $3 \mathrm{c}$ ) indicates

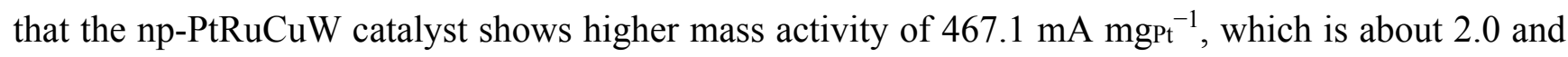
1.6 times of that for PtC and PtRu (229.5 and $287.0 \mathrm{~mA} \mathrm{mg}_{\mathrm{Pt}}{ }^{-1}$ ). It can be seen that the peak potentials are comparable for all catalysts while the ratio of the forward anodic peak current density ( $\left.I_{\mathrm{f}}\right)$ to the reverse anodic peak current density $\left(I_{\mathrm{b}}\right)$ is different. It has been studied that the electro-oxidation of methanol molecules results in the formation of current peak in the forward scan and the removal of the incompletely oxidized carbonaceous species contributes to the current peak in the reverse scan [39]. Hence, the ratio $I_{\mathrm{f}} / I_{\mathrm{b}}$ can be used to measure the tolerance to carbonaceous species [4,36,40]. The values for the np-PtRuCuW, PtC and PtRu are 1.29, 0.91 and 
1.75, respectively, which indicates the higher $\mathrm{CO}$ tolerance of np-PtRuCuW than $\mathrm{PtC}$ while shows disadvantage compared to PtRu.

The subsequent $\mathrm{CO}$ tolerance experiment was carried out to characterize our np-PtRuCuW catalyst directly. As shown in Figure 4, the CO stripping peak of np-PtRuCuW (0.47 V vs. SCE) is more positive than PtRu catalyst $(0.33 \mathrm{~V}$ vs. SCE). However, there is a remarkable negative shift (about $200 \mathrm{mV}$ ) compared to the $\mathrm{PtC}(0.67 \mathrm{~V}$ vs. SCE). It is interesting to observe that the stripping curve of np-PtRuCuW presents two CO oxidation peaks, a first peak centered at about $0.47 \mathrm{~V}$ (vs. SCE) and the second one close to $0.55 \mathrm{~V}$ (vs. SCE). Moreover, the onset potential for CO stripping is located at around $0.35 \mathrm{~V}$ (vs. SCE), which is comparable to the peak potential of PtRu. This also suggests the good $\mathrm{CO}$ tolerance of our np-PtRuCuW catalyst. Maillard et al. [41] observed that catalysts comprising Pt nanoparticles with 2 to $6 \mathrm{~nm}$ size exhibited better CO tolerance. Their observations are consistent with our results, which indicate that Pt-based alloys with ligament size of $2.0 \pm 0.3 \mathrm{~nm}$ have been successfully fabricated.

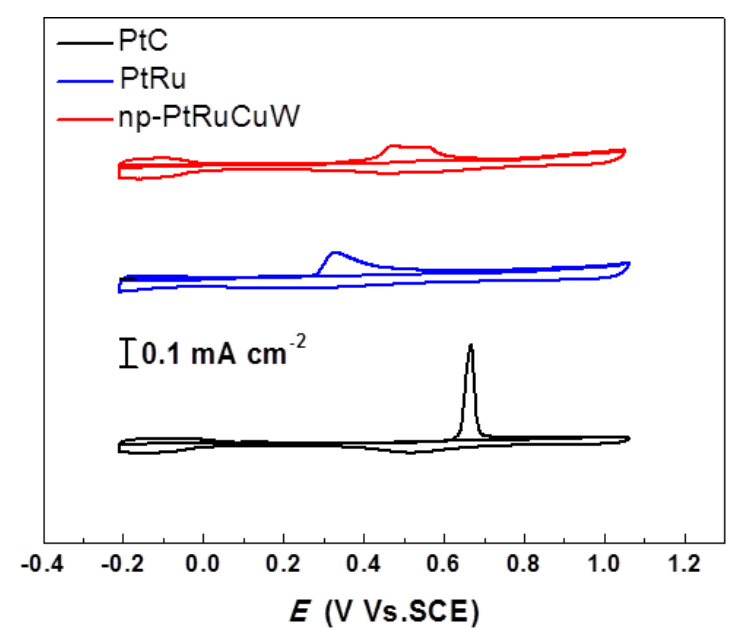

Figure 4. Electrochemical CO-stripping curves of the np-PtRuCuW, PtC and PtRu catalysts in the $0.5 \mathrm{M} \mathrm{H}_{2} \mathrm{SO}_{4}$ solution (Scan rate: $20 \mathrm{mV} \mathrm{s}^{-1}$ ).

During the oxidation of methanol on np-PtRuCuW, Pt accomplishes the dissociative chemisorption of methanol and the alloyed metals ( $\mathrm{Ru}, \mathrm{Cu}$ and $\mathrm{W}$ ) form oxyhydroxide, which extracts an active oxygen to oxidize the carbonaceous residues to $\mathrm{CO}_{2}[42,43]$. The three-dimensional bi-continuous structure with interconnected channels and nano-sized ligaments in np-PtRuCuW can facilitate the transportation of molecules and electrons, which greatly improves the reaction kinetics. On the basis of these effects, the present np-PtRuCuW alloy shows superior activity to the commercial PtC and $\mathrm{PtRu}$ catalysts. The result also indicates enhanced electrocatalytic performance compared to trimetallic (PtRuCu [27,28] and PtRuW [29,30]).

\subsection{Catalytic Activity of $n p-P t R u C u W$ towards ORR}

Figure 5a displays the $\mathrm{CVs}$ of the $\mathrm{np}-\mathrm{PtRuCuW}$ and $\mathrm{PtC}$ catalysts in the $\mathrm{N}_{2}$-saturated $0.1 \mathrm{M} \mathrm{HClO}_{4}$ solution. Similar to our experiments at anode, the reduction peak of Pt oxides shows a slight positive shift for the np-PtRuCuW catalyst than that of PtC, indicating earlier onset of Pt-O(H) reduction $[44,45]$. The polarization results for the ORR on the np-PtRuCuW and $\mathrm{PtC}$ electrodes are 
shown in Figure 5b. It is obvious that the polarization curve of the np-PtRuCuW catalyst shifts to a more positive position than PtC. At cathode, the diffusion-limited region (below $0.8 \mathrm{~V}$ vs. RHE) suggests a four-electron transfer reaction and indicates low hydrogen peroxide formation [46]. The half-wave potential of the np-PtRuCuW alloy is located at $0.877 \mathrm{~V} v$ s. RHE, $13 \mathrm{mV}$ positive shift compared to PtC catalyst (0.864 V vs. RHE). The present results indicate a greatly enhanced ORR activity of np-PtRuCuW.
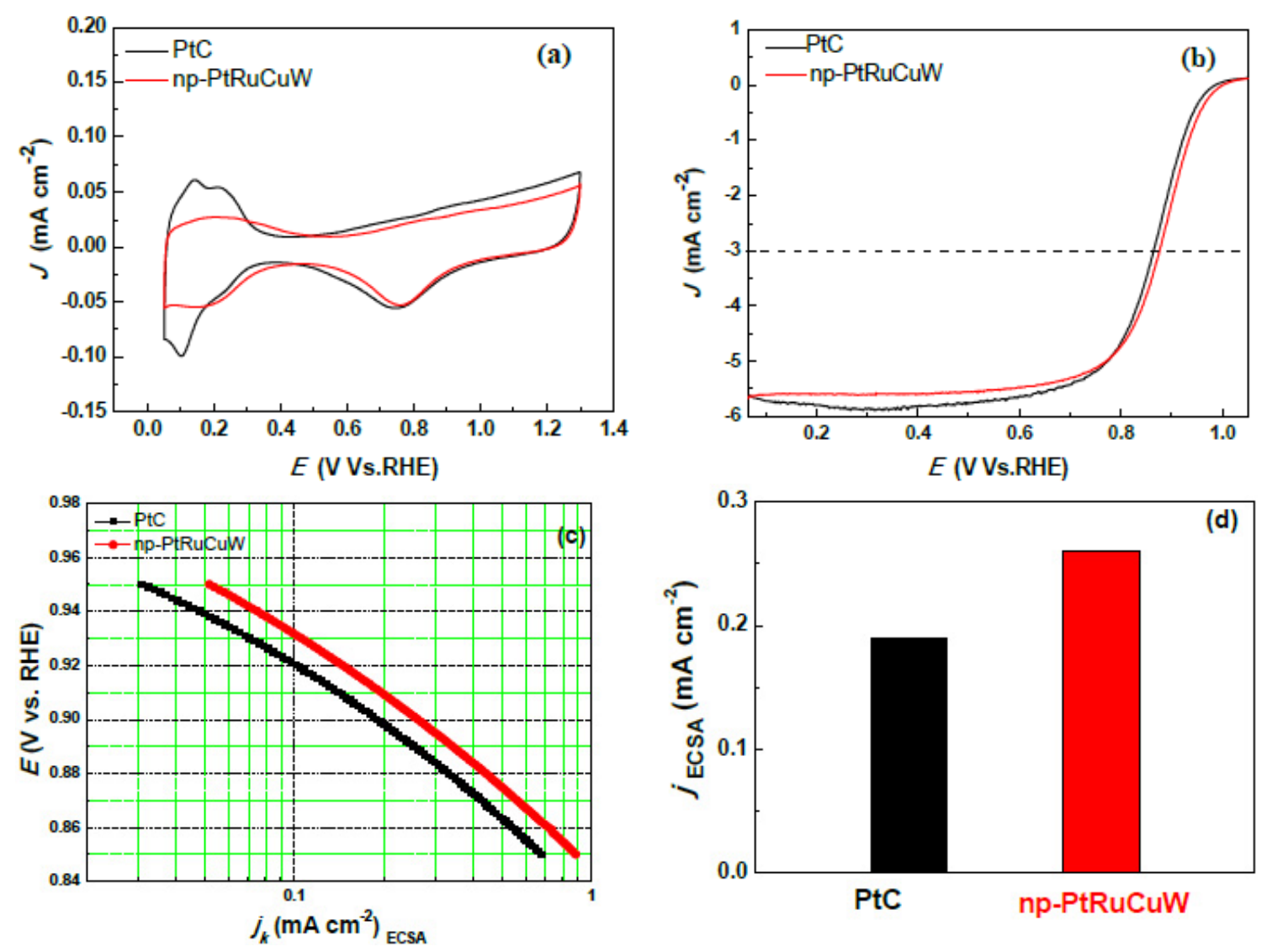

Figure 5. (a) $\mathrm{CV}$ curves of the np-PtRuCuW and PtC catalysts in the $\mathrm{N}_{2}$-purged $0.1 \mathrm{M} \mathrm{HClO}_{4}$ solution (Scan rate: $50 \mathrm{mV} \mathrm{s}^{-1}$ ); (b) ORR results in the $\mathrm{O}_{2}$-saturated $0.1 \mathrm{M} \mathrm{HClO}_{4}$ solution at $1600 \mathrm{rpm}$ (Scan rate: $10 \mathrm{mV} \mathrm{s}^{-1}$ ); (c) ECSA-normalized specific kinetic current densities $(j \mathrm{k})$; and (d) the ECSA-normalized specific kinetic current densities for the np-PtRuCuW and PtC catalysts at $0.90 \mathrm{~V}$ (vs. RHE).

According to the Tafel plots (Figure 5c), the np-PtRuCuW catalyst shows better specific activity than the commercial $\mathrm{PtC}$ at the whole selected potential region (0.85 0.95 V vs. RHE). Additionally, the Tafel curve of the np-PtRuCuW catalyst is parallel to that of the commercial PtC, which can be observed directly from the plots. This potential region corresponds to ORR when the hydroxyl species $\left(\mathrm{OH}_{a d s}\right)$ at $\mathrm{Pt}$ active sites and determines the electrode activity. Therefore, the plots demonstrate the similar ORR processes on the np-PtRuCuW and commercial PtC catalysts in acidic media [47,48]. The kinetic current densities at $0.90 \mathrm{~V}$ vs. RHE represent the activities towards ORR and were calculated by the Koutecky-Levich equation from the ORR polarization curves. The kinetic current densities were normalized by the ECSA to obtain the specific activity in Figure 5d, respectively. 
The np-PtRuCuW exhibits a higher specific activity of $0.26 \mathrm{~mA} \mathrm{~cm}{ }^{-2}$, which is 1.37 times of the commercial PtC catalyst $\left(0.19 \mathrm{~mA} \mathrm{~cm}^{-2}\right)$.

The ORR consists of four proton and electron transfer $\left(\mathrm{O}_{2}+4 \mathrm{H}^{+}+4 \mathrm{e}^{-} \rightarrow 2 \mathrm{H}_{2} \mathrm{O}\right)$, O-O breaking and $\mathrm{OH}_{\text {ads }}$ intermediates formation [46,49]. After alloying with $\mathrm{Ru}, \mathrm{Cu}$ and $\mathrm{W}$, the lattice parameter of $\mathrm{Pt}$ changes which would bring about ligand and strain effects. This will accelerate the scission of the $\mathrm{O}-\mathrm{O}$ bond and the formation of the $\mathrm{OH}_{a d s}$, thus increasing the $\mathrm{O}_{2}$ reaction rate [50,51]. On the other hand, the hydrogenation rates of $\mathrm{OH}_{\text {ads }}$ intermediates enhanced and reduced the coverage of $\mathrm{Pt}$ surface because of alloy effect [52]. These could rationalize that the present np-PtRuCuW alloy shows improved catalytic performance towards ORR relative to the commercial PtC catalyst.

\section{Experimental Section}

\subsection{Synthesis and Characterizations of $n p-P t R u C u W$}

A multi-component $\mathrm{Al}_{66} \mathrm{Cu}_{30}\left(\mathrm{Pt}_{53} \mathrm{Ru}_{32} \mathrm{~W}_{15}\right)_{4}$ alloy (nominal composition, at \%) was chosen as the precursor and prepared by milling a mixture of pure elemental powders (i.e., $\mathrm{Al}, \mathrm{Cu}, \mathrm{Pt}, \mathrm{Ru}$ and $\mathrm{W}$ with 99.9 wt. \% purity) as before [34,53]. Then, dealloying of the $\mathrm{Al}_{66} \mathrm{Cu}_{30}\left(\mathrm{Pt}_{53} \mathrm{Ru}_{32} \mathrm{~W}_{15}\right)_{4}$ alloy powders was carried out in a $1 \mathrm{M} \mathrm{HNO}_{3}$ solution at room temperature until no obvious bubbles emerged. After the facile dealloying, the samples were rinsed using distilled water and dehydrated alcohol to gain the final np-PtRuCuW catalyst.

X-ray diffractometer (XRD, Rigaku D/max-rB, Osaka, Japan) with $\mathrm{Cu} \mathrm{K \alpha}$ radiation was used to analysis the $\mathrm{X}$-ray diffractograms of the $\mathrm{Al}_{66} \mathrm{Cu}_{30}\left(\mathrm{Pt}_{53} \mathrm{Ru}_{32} \mathrm{~W}_{15}\right)_{4}$ precursor and as-dealloyed samples. The chemical compositions of the as-dealloyed samples were obtained by an energy-dispersive X-ray (EDX) analyzer in an area-analysis mode (a typical area of $50 \mu \mathrm{m} \times 50 \mu \mathrm{m}$ ). Transmission electron microscope (TEM, FEI Tecnai G2, Pleasanton, CA, USA) and high-resolution TEM (HRTEM, FEI Tecnai G2, CA, USA) were also applied to characterize the microstructure. In addition, selected-area electron diffraction (SAED) and fast Fourier transform (FFT) patterns were obtained from the corresponding images.

\subsection{Electrochemical Characterization}

The ORR and MOR measurements were performed using a standard three-electrode cell with a CHI 760E Potentiostat ( $\mathrm{CH}$ Instruments, Shanghai, China). The reference electrode was saturated calomel electrode (SCE) and the counter electrode was a bright Pt plate. The catalyst ink preparation and measurement conditions were consistent with our previous report [34,53]. For comparison, we benchmarked the electrochemical properties of the np-PtRuCuW against the commercial (Johnson's Matthey, Pennsylvania, PA, USA) PtC and PtRu catalysts under identical experimental conditions.

\section{Conclusions}

In conclusion, a novel np-PtRuCuW catalyst has been explored through the combination of a mechanical alloying with the subsequent simple chemical dealloying step. The facile and green technique shows great advantages in the design of multiple component nanostructured alloy electrocatalysts. The np-PtRuCuW catalyst with a unique ligament/channel structure shows enhanced 
catalytic activity for methanol oxidation at anode compared to $\mathrm{PtC}$ and $\mathrm{PtRu}$ catalysts. Furthermore, the catalyst also indicates enhanced catalytic activity towards oxygen reduction reaction at cathode. Our results provide a novel strategy for the design of precursor alloys and fabrication of multi-component nanoporous alloy catalysts for DMFCs.

\section{Acknowledgments}

The authors gratefully acknowledge financial support by National Natural Science Foundation of China (51371106), National Basic Research Program of China (973, 2012CB932800), Cross Disciplinary Training Project of Shandong University (2014JC004), Specialized Research Found for the Doctoral Program of Higher Education of China (20120131110017), and Young Tip-Top Talent Support Project (the Organization Department of the Central Committee of the CPC). We also acknowledge the experimental assistance from Ruhr University Bochum, Germany. Y.L. Gao acknowledges the support by Program for Professor of Special Appointment (Eastern Scholar) at Shanghai Institutions of Higher Learning (No. TP2014042).

\section{Author Contributions}

We thank our collaborators for their contributions to the manuscript. Thank Ying Wang and Qingguo Bai for the fabrication of precursor alloy. Great valuable discussions for the results were supported by Yulai Gao. Xiaoting Chen and Hao Wang carried out most of the experiment and completed documentation and the manuscript. Zhonghua Zhang is in charge of the whole work.

\section{Conflicts of Interest}

The authors declare no conflict of interest.

\section{References}

1. Kamarudin, S.K.; Achmad, F.; Daud, W.R.W. Overview on the application of direct methanol fuel cell (DMFC) for portable electronic devices. Int. J. Hyd. Energy 2009, 34, 6902-6916.

2. Zhang, G.; Xia, B.Y.; Wang, X. Strongly Coupled $\mathrm{NiCo}_{2} \mathrm{O}_{4}-\mathrm{Rgo}$ Hybrid Nanosheets as a Methanol-Tolerant Electrocatalyst for the Oxygen Reduction Reaction. Adv. Mater. 2014, 26, 2408-2412.

3. Reddington, E.; Sapienza, A.; Gurau, B.; Viswanathan, R.; Sarangapani, S.; Smotkin, E.S.; Mallouk, T.E. Combinatorial electrochemistry: A highly parallel, optical screening method for discovery of better electrocatalysts. Science 1998, 280, 1735-1737.

4. Ma, X.; Luo, L.; Zhu, L.; Yu, L.; Sheng, L.; An, K.; Ando, Y.; Zhao, X. Pt-Fe catalyst nanoparticles supported on single-wall carbon nanotubes: Direct synthesis and electrochemical performance for methanol oxidation. J. Power Sour. 2013, 241, 274-280.

5. Wang, C.; Markovic, N.M.; Stamenkovic, V.R. Advanced platinum alloy electrocatalysts for the oxygen reduction reaction. ACS Catal. 2012, 2, 891-898.

6. Ahmadi, R.; Amini, M.; Bennett, J. Pt-Co alloy nanoparticles synthesized on sulfur-modified carbon nanotubes as electrocatalysts for methanol electrooxidation reaction. J. Catal. 2012, 292, 81-89. 
7. Xu, C.; Hou, J.; Pang, X.; Li, X.; Zhu, M.; Tang, B. Nanoporous PtCo and PtNi alloy ribbons for methanol electrooxidation. Int. J. Hyd. Energy 2012, 37, 10489-10498.

8. Choi, S.-I.; Xie, S.; Shao, M.; Odell, J.H.; Lu, N.; Peng, H.-C.; Protsailo, L.; Guerrero, S.; Park, J.; $\mathrm{Xia}, \mathrm{X}$. Synthesis and characterization of $9 \mathrm{~nm}$ Pt-Ni octahedra with a record high activity of $3.3 \mathrm{~A} / \mathrm{mgPt}$ for the oxygen reduction reaction. Nano Lett. 2013, 13, 3420-3425.

9. Cui, C.; Gan, L.; Heggen, M.; Rudi, S.; Strasser, P. Compositional segregation in shaped Pt alloy nanoparticles and their structural behaviour during electrocatalysis. Nat. Mater. 2013, 12, 765-771.

10. Zhang, X.; Li, D.; Dong, D.; Wang, H.; Webley, P.A. One-step fabrication of ordered Pt-Cu alloy nanotube arrays for ethanol electrooxidation. Mater. Lett. 2010, 64, 1169-1172.

11. Sun, S.; Zhang, G.; Geng, D.; Chen, Y.; Banis, M.N.; Li, R.; Cai, M.; Sun, X. Direct growth of single-crystal Pt nanowires on $\mathrm{Sn} @ \mathrm{CNT}$ nanocable: 3D electrodes for highly active electrocatalysts. Chem. A Eur. J. 2010, 16, 829-835.

12. Zou, L.; Guo, J.; Liu, J.; Zou, Z.; Akins, D.L.; Yang, H. Highly alloyed PtRu black electrocatalysts for methanol oxidation prepared using magnesia nanoparticles as sacrificial templates. J. Power Sources. 2014, 248, 356-362.

13. Guo, J.; Zhao, T.; Prabhuram, J.; Chen, R.; Wong, C. Preparation and characterization of a PtRu/C nanocatalyst for direct methanol fuel cells. Electrochim. Acta 2005, 51, 754-763.

14. Lipkowski, J.; Ross, P.N. Electrocatalysis; John Wiley \& Sons: New York, NY, USA, 1998; Volume 3, pp. 70-200.

15. Kua, J.; Goddard, W.A. Oxidation of methanol on 2nd and 3rd row group viii transition metals (Pt, Ir, Os, Pd, Rh, and Ru): Application to direct methanol fuel cells. J. Am. Chem. Soc. 1999, 121, 10928-10941.

16. Tong, Y.; Rice, C.; Wieckowski, A.; Oldfield, E. A detailed NMR-based model for CO on Pt catalysts in an electrochemical environment: Shifts, relaxation, back-bonding, and the Fermi-Level local density of states. J. Am. Chem. Soc. 2000, 122, 1123-1129.

17. Zhou, W.; Zhou, Z.; Song, S.; Li, W.; Sun, G.; Tsiakaras, P.; Xin, Q. Pt based anode catalysts for direct ethanol fuel cells. Appl. Catal. B 2003, 46, 273-285.

18. Liu, H.; Song, C.; Zhang, L.; Zhang, J.; Wang, H.; Wilkinson, D.P. A review of anode catalysis in the direct methanol fuel cell. J. Power Sour. 2006, 155, 95-110.

19. Liu, Z.; Lee, J.Y.; Han, M.; Chen, W.; Gan, L.M. Synthesis and characterization of PtRu/C catalysts from microemulsions and emulsions. J. Mater. Chem. 2002, 12, 2453-2458.

20. Almeida, T.; Palma, L.; Leonello, P.; Morais, C.; Kokoh, K.; de Andrade, A. An optimization study of $\mathrm{PtSn} / \mathrm{C}$ catalysts applied to direct ethanol fuel cell: Effect of the preparation method on the electrocatalytic activity of the catalysts. J. Power Sour. 2012, 215, 53-62.

21. Liu, L.; Huang, Z.; Wang, D.; Scholz, R.; Pippel, E. The fabrication of nanoporous Pt-based multimetallic alloy nanowires and their improved electrochemical durability. Nanotechnology 2011, 22, 105604, doi:10.1088/0957-4484/22/10/105604.

22. Chen, Z.; Waje, M.; Li, W.; Yan, Y. Supportless Pt and PtPd nanotubes as electrocatalysts for oxygen-reduction reactions. Angew. Chem. Int. Ed. 2007, 46, 4060-4063.

23. You, T.; Niwa, O.; Tomita, M.; Hirono, S. Characterization of platinum nanoparticle-embedded carbon film electrode and its detection of hydrogen peroxide. Anal. Chem. 2003, 75, 2080-2085. 
24. Weissmüller, J.; Viswanath, R.; Kramer, D.; Zimmer, P.; Würschum, R.; Gleiter, H. Charge-induced reversible strain in a metal. Science 2003, 300, 312-315.

25. Qi, Z.; Geng, H.; Wang, X.; Zhao, C.; Ji, H.; Zhang, C.; Xu, J.; Zhang, Z. Novel nanocrystalline PdNi alloy catalyst for methanol and ethanol electro-oxidation in alkaline media. J. Power Sour. 2011, 196, 5823-5828.

26. Xu, C.; Liu, Y.; Hao, Q.; Duan, H. Nanoporous PdNi alloys as highly active and methanol-tolerant electrocatalysts towards oxygen reduction reaction. J. Mater. Chem. A 2013, 1, 13542-13548.

27. Jeon, M.K.; Cooper, J.S.; McGinn, P.J. Methanol electro-oxidation by a ternary Pt-Ru-Cu catalyst identified by a combinatorial approach. J. Power Sour. 2008, 185, 913-916.

28. Naidoo, Q.-L.; Naidoo, S.; Petrik, L.; Nechaev, A.; Ndungu, P.; Vaivars, G. Synthesis highly active platinum tri-metallic electrocatalysts using "one-step" organometallic chemical vapour deposition technique for methanol oxidation process. IOP Conf. Ser. Mater. Sci. Eng. 2012, doi:10.1088/1757-899X/38/1/012031.

29. Kang, D.K.; Noh, C.S.; Park, S.T.; Sohn, J.M.; Kim, S.K.; Park, Y.-K. The effect of PtRuW ternary electrocatalysts on methanol oxidation reaction in direct methanol fuel cells. Korean J. Chem. Eng. 2010, 27, 802-806.

30. Jeon, M.K.; Lee, K.R.; Woo, S.I. Ternary $\mathrm{Pt}_{45} \mathrm{Ru}_{45} \mathrm{M}_{10} / \mathrm{C}(\mathrm{M}=\mathrm{Mn}$, Mo and W) catalysts for methanol and ethanol electro-oxidation. Korean J. Chem. Eng. 2009, 26, 1028-1033.

31. Aricò, A.S.; Antonucci, P.L.; Modica, E.; Baglio, V.; Kim, H.; Antonucci, V. Effect of PtRu alloy composition on high-temperature methanol electro-oxidation. Electrochim. Acta 2002, 47, 3723-3732.

32. Ammam, M.; Easton, E.B. Quaternary PtMnCuX/C (X = Fe, Co, Ni, and Sn) and PtMnMoX/C $(\mathrm{X}=\mathrm{Fe}, \mathrm{Co}, \mathrm{Ni}, \mathrm{Cu}$ and $\mathrm{Sn}$ ) alloys catalysts: Synthesis, characterization and activity towards ethanol electrooxidation. J. Power Sour. 2012, 215, 188-198.

33. Qian, L.; Chen, M. Ultrafine nanoporous gold by low-temperature dealloying and kinetics of nanopore formation. Appl. Phys. Lett. 2007, 91, 083105, doi:10.1063/1.2773757.

34. Chen, X.; Jiang, Y.; Sun, J.; Jin, C.; Zhang, Z. Highly active nanoporous Pt-based alloy as anode and cathode catalyst for direct methanol fuel cells. J. Power Sour. 2014, 267, 212-218.

35. Pozio, A.; de Francesco, M.; Cemmi, A.; Cardellini, F.; Giorgi, L. Comparison of high surface Pt/C catalysts by cyclic voltammetry. J. Power Sour. 2002, 105, 13-19.

36. Lee, Y.-W.; Ko, A.-R.; Han, S.-B.; Kim, H.-S.; Park, K.-W. Synthesis of octahedral Pt-Pd alloy nanoparticles for improved catalytic activity and stability in methanol electrooxidation. Phys. Chem. Chem. Phys. 2011, 13, 5569-5572.

37. Li, H.H.; Cui, C.H.; Zhao, S.; Yao, H.B.; Gao, M.R.; Fan, F.J.; Yu, S.H. Mixed-PtPd-shell PtPdCu nanoparticle nanotubes templated from copper nanowires as efficient and highly durable electrocatalysts. Adv. Energy Mater. 2012, 2, 1182-1187.

38. He, C.; Liang, Y.; Fu, R.; Wu, D.; Song, S.; Cai, R. Nanopores array of ordered mesoporous carbons determine Pt's activity towards alcohol electrooxidation. J. Mater. Chem. 2011, 21, 16357-16364.

39. Mancharan, R.; Goodenough, J.B. Methanol oxidation in acid on ordered NiTi. J. Mater. Chem. 1992, 2, 875-887. 
40. Xu, C.; Wang, L.; Wang, R.; Wang, K.; Zhang, Y.; Tian, F.; Ding, Y. Nanotubular mesoporous bimetallic nanostructures with enhanced electrocatalytic performance. Adv. Mater. 2009, 21, 2165-2169.

41. Maillard, F.; Schreier, S.; Hanzlik, M.; Savinova, E.R.; Weinkauf, S.; Stimming, U. Influence of particle agglomeration on the catalytic activity of carbon-supported Pt nanoparticles in Co monolayer oxidation. Phys. Chem. Chem. Phys. 2005, 7, 385-393.

42. Ley, K.L.; Liu, R.; Pu, C.; Fan, Q.; Leyarovska, N.; Segre, C.; Smotkin, E. Methanol oxidation on single-phase Pt-Ru-Os ternary alloys. J. Electrochem. Soc. 1997, 144, 1543-1548.

43. Lei, H.-W.; Suh, S.; Gurau, B.; Workie, B.; Liu, R.; Smotkin, E.S. Deuterium isotope analysis of methanol oxidation on mixed metal anode catalysts. Electrochim. Acta 2002, 47, 2913-2919.

44. Zhang, X.; Choi, I.; Qu, D.; Wang, L.; Lee, C.-W.J. Coverage-dependent electro-catalytic activity of Pt sub-monolayer/Au bi-metallic catalyst toward methanol oxidation. Int. J. Hyd. Energy 2013, $38,5665-5670$.

45. Hodnik, N.; Jeyabharathi, C.; Meier, J.C.; Kostka, A.; Phani, K.L.; Rečnik, A.; Bele, M.; Hočevar, S.; Gaberšček, M.; Mayrhofer, K.J. Effect of ordering of $\mathrm{PtCu}_{3}$ nanoparticle structure on the activity and stability for the oxygen reduction reaction. Phys. Chem. Chem. Phys. 2014, 16, 13610-13615.

46. Stephens, I.E.L.; Bondarenko, A.S.; Grønbjerg, U.; Rossmeisl, J.; Chorkendorff, I. Understanding the electrocatalysis of oxygen reduction on platinum and its alloys. Energy Environ. Sci. 2012, 5, 6744-6762.

47. Hu, Y.; Jensen, J.O.; Zhang, W.; Cleemann, L.N.; Xing, W.; Bjerrum, N.J.; Li, Q. Hollow spheres of iron carbide nanoparticles encased in graphitic layers as oxygen reduction catalysts. Angew. Chem. Int. Ed. 2014, 53, 3675-3679.

48. Kongkanand, A.; Kuwabata, S.; Girishkumar, G.; Kamat, P. Single-wall carbon nanotubes supported platinum nanoparticles with improved electrocatalytic activity for oxygen reduction reaction. Langmuir 2006, 22, 2392-2396.

49. Guo, S.; Zhang, S.; Sun, S. Tuning nanoparticle catalysis for the oxygen reduction reaction. Angew. Chem. Int. Ed. 2013, 52, 8526-8544.

50. Toda, T.; Igarashi, H.; Uchida, H.; Watanabe, M. Enhancement of the electroreduction of oxygen on Pt alloys with Fe, Ni, and Co. J. Electrochem. Soc. 1999, 146, 3750-3756.

51. Toda, T.; Igarashi, H.; Watanabe, M. Role of electronic property of Pt and Pt alloys on electrocatalytic reduction of oxygen. J. Electrochem. Soc. 1998, 145, 4185-4188.

52. Zhang, J.; Vukmirovic, M.B.; Xu, Y.; Mavrikakis, M.; Adzic, R.R. Controlling the catalytic activity of platinum-monolayer electrocatalysts for oxygen reduction with different substrates. Angew. Chem. Int. Ed. 2005, 44, 2132-2135.

53. Chen, X.; Si, C.; Gao, Y.; Frenzel, J.; Sun, J.; Eggeler, G.; Zhang, Z. Multi-component nanoporous platinum-ruthenium-copper-osmium-iridium alloy with enhanced electrocatalytic activity towards methanol oxidation and oxygen reduction. J. Power Sour. 2015, 273, 324-332.

(C) 2015 by the authors; licensee MDPI, Basel, Switzerland. This article is an open access article distributed under the terms and conditions of the Creative Commons Attribution license (http://creativecommons.org/licenses/by/4.0/). 